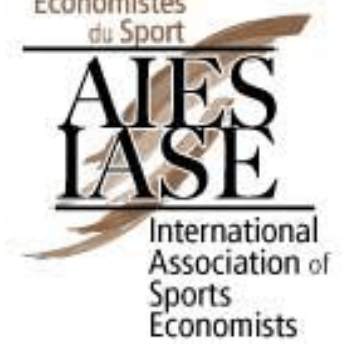

Working Paper Series, Paper No. 06-08

\title{
Rottenberg and the Economics of Sport after 50 years: An Evaluation
}

\author{
Peter J. Sloane ${ }^{\dagger}$
}

June 2006

\begin{abstract}
Simon Rottenberg's seminal 1956 article in the Journal of Political Economy, 1956, is generally accepted as the starting point for the development of the economics of sport. While he recognised that certain features of professional sports leagues were unusual he saw little reason to treat this industry any differently from a conventional industry. He discusses the importance of uncertainty of outcome, the monopsonistic nature of the labour market, the nature of the product and demand (attendances). He considers alternatives to the reserve clause, such as equal revenue sharing, maximum salary limits, equal market franchise distribution and roster limits. Each of these is rejected in favour of a free market solution which, on the basis of the invariance principle, he suggests will perform just as well as the reserve clause in allocating talent to where it is most productive. The ensuing literature has focused on all these issues, many of which have created considerable debate amongst sports economists. In particular the assumption of profit maximisation has been challenged and a divergence of views, reflected in the so-called North American and European models of sports leagues has emerged. Over the last 50 years sports leagues have expanded, TV markets have opened up and legal challenges to existing practices have multiplied. This paper seeks to evaluate Rottenberg's contribution to a rapidly expanding field and to judge its relevance today.
\end{abstract}

JEL Classification Codes: J0, L0, L83

Keywords: sports, monopsony, monopoly power

${ }^{\dagger}$ University of Wales Swansea and IZA, p.j.sloane@swansea.ac.uk 


\section{INTRODUCTION}

The economics of sport can truly be said to have begun with Simon Rottenberg's seminal paper on the baseball players market in the Journal of Political Economy 1956, some eight years before Walter Neale’s well known paper in the Quarterly Journal of Economics (which failed to cite it), with J.C.H. Jones' contribution on the National Hockey League appearing a year later in the Canadian Journal of Economics. In Europe the first academic journal papers, both on football, were by Sloane (1969) and (1971). Surprisingly Rottenberg's 1956 paper appears to have been his sole contribution to the subject, apart from an invited paper in the founding issue of the Journal of Sports Economics (Rottenberg, 2000). The same journal also included another invited paper on Rottenberg's contribution to celebrate the golden anniversary of the original paper, (Fort, 2005). That paper adopted a purely North American perspective with all 25 references being US in origin. This paper attempts to complement Fort's paper by considering the European model alongside the North American one and attempting to identify which issues remain the most contentious in the field.

The defining feature of Rottenberg's paper was his belief that the economics of professional sports leagues could be analysed using the same economic framework as for any other industry. He did, however, recognise two unusual characteristics - the fact that monopsony power took an extreme form in this industry and that competitors must be of approximately equal size if any of them are to be successful. He did not consider the possibility of non-profit maximising behaviour, though in his 2000 paper he does note that investors might derive psychic income from their involvement and thus be prepared to accept losses. 


\section{THE KEY FEATURES OF PROFESSIONAL TEAM SPORTS}

Rottenberg sketched out the main features of major league baseball and these, described by Fort as the eleven anchors of the sports economics literature, have been taken to apply to other professional team sports leagues. They are :-

1) the labour market is monopsonistic.

2) the product market is monopolistic.

3) there are rich and poor clubs, based on attendances as opposed to population size.

4) attendances are a function of some key variables.

5) the reserve clause does not provide an equal distribution of talent.

6) the advantages of the draft system are largely illusory.

7) the prospect of very high salaries attracts an over-abundance of players, leading to wide salary dispersion.

8) baseball team owners are rational profit maximisers.

9) differences in the quality of rivals should not be 'too great' in order to produce a successful product (uncertainty of outcome).

10) the free market is as efficient as the reserve clause in terms of resource allocation (the invariance principle).

11) the demise of the reserve clause would have no impact on the amount of training or the quality of play

\section{(a) THE INVARIANCE PRINCIPLE}

The invariance principle (IP) and uncertainty of outcome (UOO) are crucial, but controversial, elements of the economics of sport. Fort refers to the former as "the rock solid foundation of much of the analysis in sports economics” and points out that 
it is an application of the Coase Theorem (CT) which actually preceded the publication of the latter by some four years. The Coase Theorem itself states that in competitive markets and given that resources are freely exchangeable the distribution of their ownership among agents is irrelevant to ensuring that they are used efficiently. This assumes not only perfect competition, perfect information, and the absence of transaction costs ${ }^{1}$, but also the absence of wealth and income effects. ${ }^{2}$ It is at least questionable whether these assumptions hold in professional team sports, given the presence of product market monopoly. In such a case it is possible that the theory of the second best (Lancaster and Lipsey, 1956) ${ }^{3}$ applies. This theory suggests that in the absence of being able to obtain all the conditions necessary for the existence of Pareto optimality then the second best position can only be reached by departing from the other Paretian conditions. In the team sports context Rottenberg's claim on page 258 that "free markets would give as good aggregate results as any other kind of market ...... in which all firms must be nearly equal if each is to prosper”, (my italics) might be challenged. Rottenberg calls upon the law of diminishing returns and economies of scale to support his argument. In the former case, if a larger club continues to purchase additional players the total product will eventually increase at a decreasing rate and the latter occurs when one team becomes

\footnotetext{
${ }^{1}$ It has recently been shown that ex ante transactions costs may lead to a failure of the Coase Theorem or at least the strong version in which the theorem is interpreted as guaranteeing an efficient outcome regardless of the way in which property rights are assigned. Anderlini and Felli (2001 and 2006) show that there is always an equilibrium for both players never to pay ex ante costs or agree on a division of the potential surplus, although the ex ante costs are strictly lower than the surplus itself. Moreover under certain assumptions this is the unique equilibrium outcome. One of these assumptions is that the distribution of the ex ante transactions costs across the players is sufficiently asymmetric. This seems quite likely in the context of European leagues in particular.

${ }^{2}$ There have hardly been any discussions in the ensuing literature of whether these assumptions are likely to apply in practice: Cymrot, Dunlevy and Even (2001) did, however, examine changes in the competitive environment to test whether this affected the migration pattern of players to where their individual potential productivity gains from changing teams were greatest, which is a direct test of the Coase Theorem. Since both free agent and non free agent players are equally responsive to predicted gains from migration this is taken as support for the Coase Theorem. However, they recognise that the results would be more convincing if they were supported by more years of data and others have found contrary results (e.g. Daly and Moore, 1981).

${ }^{3}$ Note this was published in the same year as Rottenberg's paper and he may not have been aware of it.
} 
so superior to the rest that interest wanes. Both of these outcomes depend on uncertainty of outcome being important. Thus, profit maximisation requires in this situation that star players be moved to less successful clubs. There are two problems here. First, neither the fans nor the players will be happy with the sale of good players to inferior clubs. Second, if there is a large disparity in the size of clubs, the marginal revenue products may be incapable of being equalised across clubs. ${ }^{4}$ Indeed, many smaller clubs maintain salary limits on the grounds that to pay more would lead to financial ruin. This is much more likely to be the case in Europe than in North America, since in the former case the larger size of leagues for a given population means that some clubs in the major leagues are very small. Further, leagues are organised within countries with disparate populations, and the most successful clubs in each country compete in lucrative European wide club competitions. This means that the more successful club in small countries may need to be 'too strong' for domestic competitions to have any hope of being successful in European wide competitions. Under these circumstances it may be necessary to rig the market to ensure that there is sufficient sporting competition.

Rottenberg neglected the possibility that externalities might frustrate the efficient allocation of playing skills. This possibility was first raised by Neale (1964), but has also been emphasised by a number of other authors. Thus, Demmert (1973) notes that increases in the skill level of above average teams will result in diseconomies which are external to the particular club but internal to the league as a whole ${ }^{5}$, while the reverse applies to improvements in the skill levels of below average teams. Both

\footnotetext{
${ }^{4}$ Thus, in North America Burger and Walters (2003) find that baseball teams in the largest markets value a given player six times as much as those in the smallest markets, suggesting no inherent tendency towards competitive balance.

${ }^{5}$ Vrooman (1996) calls this the Yankee paradox
} 
Demmert and Daly and Moore (1981) doubt whether clubs will take into account such externalities as the transactions costs associated with these effects are sufficiently large in an $n>2$ team league to make this unlikely. A further problem is that a player's talent may be team specific (or what Vrooman refers to as the irreversibility proposition). ${ }^{6}$ Added to this is the likelihood that there may be a tendency to overbid for players (the winners' curse) as information asymmetries and uncertainty may imply that the team which values a player's worth correctly has less chance of signing him than a team which overestimates his value (Cassing and Douglas, 1990). More recently Whitney (2005) has shown that there is a difference between trading players already in the league and signing players from outside the league (a common phenomenon in Europe). Restricting transactions to the external market leads to a more even distribution of playing skills than recourse to the internal market as this does not directly diminish the talent level of other clubs, but instead shifts resources away from the league’s revenue maximising optimum. This leads Whitney to dispute El Hodiri and Quirk’s assertion that syndicated control and decentralised franchises generate the same distribution of talent. In a $n>2$ team league decentralised leagues become less competitively balanced. He also shows that talent migration from weaker to stronger teams unambiguously raises the winning percentages of third party teams, who gain more from improved performance against the weaker of the two teams than they lose from the weaker performance against the stronger team. This, however, makes no allowance for uncertainty of outcome in the context of the championship race. Yet, it points to the fact that one cannot always generalise from a two team league model to an $n>2$ team league. Further, as Zimbalist (2002)

\footnotetext{
${ }^{6}$ Kendall (2003) has recently examined the related issue of spillovers in relation to basketball. Under certain conditions spillovers may cause a worker's marginal productivity to differ across different teams. His empirical results suggest significant spillovers exist in relation to offensive productivity, but there is little evidence that market sorting based on such spillovers exists.
} 
observes, the important question of how much competitive balance is required for joint profit maximisation remains unanswered.

In the ensuing literature the invariance principle has also been used to argue that increased gate-sharing will have no effect on competitive balance. Its use here seems, however, to be misguided, as gate-sharing is designed to alter the most efficient uses of playing talent. Many authors have followed Quirk and Fort (1995) in portraying the impact of revenue-sharing as a downward parallel shift in the marginal returns to winning schedule, resulting in no change in the winning percentages of a large and small club in a two-club league. Yet, it is not clear why this curve should shift downwards as a result of revenue-sharing, as the schedule is presumably derived from the fans' demand curve for winning, Indeed, fans may not even be aware of the actual revenue-sharing arrangements for the games they watch. The puzzling part of the standard diagrammatic representation is that no sharing actually takes place; both teams are simply taxed on their home games. ${ }^{7}$ What in fact we have, assuming that the large city team has a larger stadium and attracts larger crowds than the small city team, is a classic ad valorem tax and ad valorem subsidy system in which net revenue transfers from the large club to the small club. This will cause the supply schedule of the large club (the marginal cost of providing a winning team) to swivel upwards from the origin and that of the small club to swivel down from the origin by identical amounts. In other words the willingness to supply a winning team decreases for the large club and increases for the small club leading to an improvement in competitive balance. Despite this unambiguous text-book prediction sports economists have

\footnotetext{
${ }^{7}$ It seems necessary to distinguish home and away games since the small club gains more from its away games than it gives up from its home games. Since the same number of points accrues from an away game as from a home game, the marginal returns from winning away cannot be ignored. It is necessary to win some away games in order to remain in contention for the league title.
} 
continued to blur the picture by arguing that gate-sharing has no impact on competitive balance (the majority view), that it improves competitive balance (Marburger, 1997, Kesenne, 2000) or that it worsens competitive balance (Szymanski and Kesenne, 2004). This is hardly a satisfactory state of affairs and contrasts markedly with the views of sports organisers themselves and the courts. Thus, in the 1995 Bosman case heard by the European Court of Justice, the Advocate-General, Heinz Otto Lenz, actually advocated more equal gate-sharing as a means of offsetting the weakening of the restrictions of the existing transfer system then operating in European football.

In the standard models the attainment of equilibrium is dependent on constant marginal costs of acquiring talent, but this assumption is hardly realistic even for the world market when star talent is in such short supply. Profit maximisation, if indeed this is the maximand, requires marginal cost to equal marginal revenue (or returns to winning) for each individual club. There is no mechanism for ensuring that marginal returns are equalised for all clubs in the league. That would only occur if clubs had the same marginal cost and marginal revenue curves, which is unlikely given the spatial monopoly nature of the industry and discontinuities which prevent equal population densities being achieved for all clubs. The achievement of joint profit maximisation for the league as a whole may, therefore, be constrained.

\section{(b) UNCERTAINTY OF OUTCOME}

The second pillar of Rottenberg's analysis was the uncertainty of outcome hypothesis and it is clear that what he had in mind here was uncertainty of match outcome. Thus, in Rottenberg (2000) he states 'the highest degree of uncertainty occurs when the 
probability that any given team will win in any given game is 0.5 .' Later authors have identified at least three forms of uncertainty of outcome. These are (see Cairns et al., 1985)

- $\quad$ short-run uncertainty of match outcome.

- medium term or seasonal uncertainty of outcome, implying either

- the more teams in contention for the league title the higher attendances, or

- the longer one's own team remains in contention the higher attendances.

- long term uncertainty of outcome, which refers to lack of domination by one or more clubs over a number of seasons. Bizzachi et al. (2003) refer to this as dynamic competitive balance.

As Dawson and Downward (2003) observe 'despite the centrality of uncertainty of outcome to sports economics, there has been surprisingly little conceptual discussion of the problematic nature of its measurement', and evidence in its favour from most studies of attendance demand is unconvincing, as in some cases the proxy measure is insignificant or where it is significant the size of the effect is relatively small. This could simply be a reflection of the inadequacy of the proxy measures or a failure to include all three forms of uncertainty in the estimating model. Further, it cannot be assumed that the three types are equivalent in importance or act independently of the others. For example, match uncertainty of outcome may depend for its significance on the state of seasonal uncertainty of outcome. Once clubs are out of contention (either for the title or promotion and relegation) close matching will be unimportant. Indeed, the expected signs of match uncertainty may change over the season. A 
match between the top and bottom club towards the end of the season will be much more exciting than a match between two middle of the table teams. These two variables should, therefore, be used interactively in estimating equations, though this is rarely, if ever, done. Short-run measures include betting odds and league standings measured in various ways. The former may be subject to long-shot bias and may be misleading if not entered in quadratic form. The latter do not capture historical strengths of each team (see Dawson and Downward, 2003) and ignore completely notions of home advantage. Teams will, in fact, be most closely matched when the home team is a number of places behind the away team prior to the match. As Cairns et al. (1986) note a further criticism is that the measures used neglect the role played by consumer expectations, and whether the home and away sides have been improving or declining in performance over recent matches. One worthwhile development would be the introduction of an adaptive expectations model.

Seasonal uncertainty is generally measured rather crudely, such as the standard deviation of winning percentages over the season, or a variable representing the average number of clubs in contention for the championship. A more sophisticated measure was used by Jennett (1984). He measures the championship significance of matches as the reciprocal of the number of matches required to win the championship (measured ex post). He estimates its significance both for the home and the away team. Again a measure of one team's expected performance relative to that of its rivals in terms of being in contention would be better but difficult to estimate.

Long-run domination has been less frequently measured than the above. Exceptions are Humphreys (2002) and Bizzachi et al. (2003). The former notes that variations in 
winning percentages over a number of seasons can be measured in two different ways - the within season variations in winning percentages of different teams and the within season variation in winning percentages across all teams. These are combined into a competitive balance ratio which turns out to be statistically significant. Bizzachi et al. consider the cumulative frequency of teams entering the top $\mathrm{k}$ ranks of a league (ordered by win percentages), but expansion of leagues in North America and changes in the composition of teams through promotion and relegation in Europe confuse the picture.

When any of these measures are included in regressions attempting to explain attendances, there are a number of other problems to be considered. Many spectators have season-tickets which implies that long-run uncertainty of outcome only is relevant to the decision to buy a season ticket, while for those paying at the gate shortrun and medium term uncertainty are the relevant variables. Because of data problems few attendance regressions run separate equations for the two types of spectator. In many cases the sell-out of tickets means that demand is unobservable. This suggests that attendance studies should focus more on lower leagues where this is less of a problem. In any event tobit estimation is required, though this is not often utilised.

One way round these problems is to examine uncertainty of outcome in relation to television broadcasts. This has been done by Forrest et al. (2005) who consider both the broadcaster's choice of which games to show and what determines the size of the TV audience for each game. They analyse Sky's contract with the English Premier League in Football over the period 1993-4 to 2001-2. While Sky has to select games 
shown prior to Christmas before the start of the season, after Christmas it can select games at short notice. In the latter period a probit model suggests that both match significance and uncertainty of outcome are each important. The OLS regressions for the size of TV audiences indicate that uncertainty of outcome is significant at the 1 per cent level in the second half of the season. But the effect is small - improving uncertainty of outcome by one standard deviation would raise predicted audience size by only 6.3 per cent. However, the authors do not include a seasonal uncertainty measure. Further work is clearly called for before there are firm conclusions to be drawn on the impact of uncertainty of outcome on spectator interest.

\section{(c) OBJECTIVES}

Rottenberg is consistent in arguing that team owners are rational profit maximisers. Yet as Fort (2000) notes 'with few notable exceptions there is nothing more pervasive in the literature on European sports than the idea that teams do not pursue profit (Sloane, 1971; the review in Cairns, Jennett and Sloane, 1985). ${ }^{8}$ Fort goes on to suggest, without providing any evidence other than US experience, that economic profit unlike accounting profit is positive. ${ }^{9}$ Team owners and boards of directors, he suggests, again without any European evidence, gain access to influential business people and politicians, which can enhance profits in other non-sports businesses. But if this were true why do so many European sports clubs enter administration? Between 2001-2003 at a time when turnover was growing rapidly, 14 English football

\footnotetext{
${ }^{8}$ That is not to say that there are no examples of sportsman owners in North America. There is an attempt to model this in Vrooman (2000) who also distinguishes the Steinbrenner effect which implies that a syndicated sportsman owner has the incentive to expand the talent level of a club beyond that of the sole sportsman owner.

${ }^{9}$ Fort and Quirk (2004) repeat the same arguments. They also cite Moorhouse (1999) as suggesting there are problems with the data used by those making the WPM argument, when he does no such thing. The data he uses are restricted to transfer fees and the question of their concentration among a few clubs.
} 
clubs entered administration and were effectively insolvent, and the finances of many clubs elsewhere in Europe including, in particular, Italy, are in an equally dire situation. Fort acknowledges that in contrast to the profit maximising case gate revenue sharing can improve competitive balance where teams attempt to maximise games won subject to a break even constraint. (Kesenne, 1995 and 1999). He goes on to note, however, that theory predicts that in the above case talent will be hired until a team's winning per cent is equal to the ratio of the team's total revenue to the league's total revenue, whereas in a league of profit maximising firms talent will be hired until its contribution to team revenue is equal to its price. Why he then asks does talent appear to move from team to team according to marginal considerations rather than relative revenue considerations? But where is the evidence for this? Rottenberg suggested that if a team became 'too strong' it should sell players to a weaker team where the contribution to total revenue is highest. In practice most transfers of talented players in Europe are from weaker to stronger teams (Carmichael and Thomas, 1993, Carmichael, Forrest and Simmons, 1999). The second question Fort poses is whether a league of winning per cent maximising teams can survive when the power of profits seems likely to undermine it both from within and without the league. However, rival leagues are absent in Europe and sportsmen owners may be able to withstand such pressure. Thus, Roman Abramovich, who took over Chelsea, has clearly pursued non-profit maximising behaviour, since in successive years the club lost $£ 88$ million and $£ 140$ million. The idea that profit maximising teams will drive out winning per cent maximising teams ignores the external costs imposed on other teams by the latter strategy. At an international level Fort argues that a profit-maximising league could buy talent from break-even leagues in other countries and became dominant, so that fan pressure would lead to the adoption of 
profit maximisation strategies in these countries. There is more weight in this argument, but in practice there is a tendency for players to move from small country to large country leagues and if the latter are win maximisation leagues this would not be corrected by a move to profit maximisation in the small leagues. Further, negative fan pressure would be more apparent in the case of a profit maximisation 'running behind' strategy than it would with a winning per cent maximisation strategy.

Little work has been done on how to distinguish between the two types of league. An exception is Fort and Quirk (2004) who show that a league of winning percentagemaximising owners will have higher talent costs and greater demand for talent than in the profit-maximising case. They also suggest that the level of competitive balance between the two types of league is indeterminate. Further, they argue that nudging owners towards one structure or the other may generate more efficient gains in competitive balance than altering incentives (such as revenue-sharing) given the league structure. As they state finding a valid empirical test of their model's implications will be challenging and this is especially the case if a mixture of objectives is found in any particular league. As Zimbalist (2004) suggests, 'the likelihood is that owner objectives are both more nuanced and more varied than is allowed in the literature ....... and the next task for modelling the behaviour and performance of a sports league is to take fuller account of this probable diversity of ownership objectives within a given league.’ A further issue, hardly touched upon in the literature is the objective function of the league organisation itself. This is often portrayed as joint profit maximisation in a league with profit maximising clubs, but could equally be the case with a league with win maximising clubs, as win maximisation has no meaning as an objective function for the league itself. 


\section{(d) OPEN VERSUS CLOSED LEAGUES}

Rottenberg did not consider in detail the operation of leagues, believing that the normal operation of market forces would bring about socially optimal outcomes with respect to league size, the geographic distribution of teams and the quality of the industry's product, (2000). There is no recognition that there are choices to be made with respect to the type of league organisation.

The relative merits of open versus closed leagues has been a much detailed issue in the recent sports economics literature. By maximising the monopoly power of incumbents potential economic rents may be higher in a closed league, but at the cost of more inefficiency. As Noll (2002) observes an open league will tend to raise team quantity because there is an incentive to buy better players to gain promotion or stave off relegation. Promotion and relegation can also increase fan interest because a higher proportion of games over the season will matter. On the other hand, promotion and relegation may force a departure from the optimal distribution of teams across divisions as superior top division teams are replaced by inferior lower division teams in terms of gate drawing potential. It is presumably for this reason that historically in the English Football League the bottom teams were not automatically relegated into non-league football, but could apply for re-election, often gaining more votes than potential league entrants. European Leagues, as Noll notes, have greater revenue disparities than the major leagues in the US. This reflects the fact that there is no attempt to limit the supply of teams in order raise profitability. There is a greater density of teams in Europe in relation to population, so that small town teams are often found even in the top divisions. This makes comparison of the relative potential efficiency of open and closed leagues somewhat difficult to judge. Thus, Buzzachi, 
Szymanski and Valletti (2003), who also find that soccer leagues are much less balanced than the US majors attribute this fact to the greater number of competitive restrictions in the former including more equal gate sharing, collective merchandising, draft rules, salary caps and other measures. They then pose the question why have European leagues bodies not adopted such redistribution practices to a greater extent? They suggest two possibilities are that competitive balance does not matter to fans or they are indifferent to dominance by a small number of teams. There is, however, a third potential explanation. The most successful national teams gain entry into European club competitions and it may be necessary to be 'too strong' in terms of domestic competitions to compete successfully in Europe. Any attempt to impose redistributive rules will be resisted by the top teams and if threatened could lead to breakaway European Leagues. Thus, the G14 group of major European clubs have threatened to form a closed European super league. In response UEFA, the governing body for soccer in Europe, has threatened the G14 clubs with expulsion from domestic competitions, issuing a statement of core principles and beliefs, passed unanimously by the 52 member countries, which includes the following statement

"Football is about fairness, opportunity, excitement and variety. It is not a closed shop, where only the richest and most powerful are invited to the table. UEFA will not tolerate a structure or system where smaller clubs, smaller nations and all their supporters never have the chance to follow their dream. This is not what UEFA is about, this is not what Europe is about, this is not what football is about.

These principles reflect ...... that football is not just a money-making exercise, not just a business. We have rules and principles that reflect our views and which protect the interests of our sport and the millions of fans. 
Among these principles is the rule that clubs must release players for the national team.”

These principles have not, however, prevented UEFA from making large profits from European club competitions.

The club versus country debate is another issue for which there is no US parallel. A Belgian club, Royal Charleroi, are suing the sports overall governing body, FIFA, for $£ 864,000$ in damages after one of their players, Abdelmajid Oulmers was injured on international duty with Morocco, on the grounds that the player's absence preventing the club from gaining entry into European competition. Charleroi's costs are being met by the G14 clubs, who are also claiming £595 million from FIFA for compensation for the release of their players for international duty. In cricket and rugby union this issue has been dealt with by having international players on central contracts under which appearance for the national teams has priority over club competitions But in these sports income from national competitions, such as test matches, dominates income from club competitions.

In conclusion one can only concur with Buzzachi et al., who suggest that "while it is clear that there are many differences, the comparative study of North American and European leagues is still at an early state..... (and) further research is required to understand the consequences of institutional differences.” 


\section{COMPETITION POLICY AND SPORT}

It is clear that Rottenberg believed that no special treatment was required for sport in relation to anti-trust policy, while in practice this certainly has not been the case as exemplified in the 1922 Supreme Court decision that MLB was exempt from the antitrust policy and the passing of the 1961 Sports Broadcasting Act which allowed league wide sales of national broadcast rights for the majors. In Europe the EU stance is based on three general principles; namely, to take account of the special characteristics of sport, to apply the competition rules in a manner that does not question the regulatory authority of sporting organisations over genuine sporting rules and to preserve the social and cultural functions of sport. Following the 1995 European Court of Justice ruling in the Bosman case, the Commission has become increasingly interventionist, however, in negotiating a new form of player contract in 2001 with FIFA and UEFA and in the same year issuing a statement objecting to the collective sale of broadcasting rights to UEFA's European Champions League Competition, although this was eventually agreed to subject to significant restrictions. Earlier the UK restrictive Practice Court had upheld the right of the English Premier League to negotiate on behalf of all member clubs in a case involving the broadcaster BskyB. However, in 2002 the Commission opened a formal investigation suggesting that the Premier League was being anti-competitive in selling exclusive rights to a single domestic broadcaster and in preventing its 20 member clubs from making individual deals. The current Premier League tender document covering the three seasons from 2007-8 is split into six packages of 23 games with no single broadcaster able to purchase all six of them which it hopes will be approved by the Commission. The importance of this issue is illustrated by the fact that whilst in 1992 Premiership club obtained $£ 82$ million from gate receipts, $£ 15$ million from broadcasting and $£ 73$ 
million from commercial activities by 2003 these figures were £363 million, £843 million and $£ 340$ million respectively, so that broadcasting is now the dominant source of income. Distribution of revenue from domestic television rights is based on 50 per cent shared equally, 25 per cent positively related to playing performance in the league and 25 per cent on the basis of the number of games shown for each club. This results in a ratio of 2.4 of top to bottom club income, which has been fairly constant, but because of the increase in the size of this income the gap between the top and bottom club has increased from $£ 1.3$ million in $1992-3$ to $£ 19.3$ million in 2003-4, thereby threatening competitive balance. Perhaps the Commission should have focused on this aspect of the sale of broadcasting rights, but it has yet to develop a coherent policy in relation to competition law and sports. It is also significant that the stance in Europe in relation to such policy seems harsher than that in North America.

\section{CONCLUSION}

Rottenberg's contribution to the development of the economics of sport should not be under-estimated. Many of the issues he raised have formed a significant part of the ensuing literature. However, whether it is reasonable to treat professional team sports as inherently no different than a conventional industry can certainly be challenged. Differences in objectives do appear to matter and team sports leagues may be inherently unstable, especially if it is difficult to internalise externalities. It is also sometimes inappropriate to assume that the predictions of two club league models can be safely generalised to $n>2$ league models. It should be emphasised that Rottenberg's analysis assumes that competitors are of approximately equal size, an assumption which seems truer of North America than of Europe. He probably over- 
emphasised the importance of gate revenue relative to broadcasting and commercial income, though to some extent their relative importance has changed since he wrote. Above all the economics of sport has, following his lead, focused on team sports to the relative neglect of non-team and participatory sports. It seems necessary to redress this imbalance as the economic issues surrounding these are of equal importance as in the case of professional team sports. It is also important that sports economists give clearer advice to sports administrators on issues such as revenue sharing and salary caps than has been the case in the past. 


\section{REFERENCES}

Anderlini L. and Felli L. Costly Bargaining and Renegotiation, Econometrica, Vol. 68, 2001, pp 377-411

Anderlini L. and Felli L. Transaction Costs and and the Robustness of the Coase Theorem, Economic Journal, Vol. 116, No. 508, January, 2006, pp 223-245

Burger J.D. and Walters S.J.K. Market Size, Pay and Performance: A General Model and Application to Major League Baseball, Journal of Sports Economics, Vol. 4, No. 2, May, 2003, pp 108-125

Buzzachi L., Szymanski S. and Valletti, T.M. Equality of Opportunity and Equality of Outcome: Open Leagues, Closed Leagues and Competitive Balance, Journal of Industry, Competition and Trade, Vol. 3, No. 3, 2003, pp 167-186

Cairns J., Jennett N. and Sloane P.J. The Economics of Professional Team Sports: A Survey of Theory and Evidence, Journal of Economic Studies, Vo. 13, No. 1, February, 1986, pp 1-80

Carmichael F., Forrest D. and Simmons R. The Labour Market in Association Football: Who Gets Transferred and for How Much, Bulletin of Economic Research, Vol. 51, No. 2, April 1999, pp 175-180

Carmichael F. and Thomas D. Bargaining in the Transfer Market: Theory and Evidence, Applied Economics, Vol. 25, 1993, pp 1467-1476

Cassing J. and Douglas R.W. 'Implications of the Auction Mechanism in Baseball's Free Agent Draft, Southern Economic Journal, Vol. 47, No. 1, 1980, pp 190-212

Cymrot D., Dunlevy J. and Even W. Who's on First? An Empirical Test of the Coase Theorem in Baseball, Applied Economics, Vol. 33, 2001, pp 593-603

Daly G. and Moore W.J. Externalities, Property Rights and the Allocation of Resources in Major League Baseball, Economic Inquiry, Vol. XIX, No. 1, 1981, pp 77-95

Dawson A. and Downward P. Measuring short-run Uncertainty of Outcome in Sporting Leagues: A Comment, Journal of Sports Economics, Vol. 6, No. 3, August, 2005, pp 303-313

Demmert H.G. The Economics of Professional Team Sports, Lexington Books, D.C. Heath, Lexington MA, 1973

El Hodiri M. and Quirk J. An Economic Model of a Professional Sports League, Journal of Political Economy, Vol. 79, 1971, pp 1302-1319

Forrest D., Simmons R. and Buraino B. Outcome Uncertainty and the Couch Potato Audience, Scottish Journal of Political Economy. Vol. 52, No. 4, September, 2005, pp 641-661 
Fort R. European and North American Sports Differences: Scottish Journal of Political Economy, Vol. 47, No. 4, September, 2000, pp 456-470

Fort R. The Golden Anniversary of the Baseball Players' Labor Market, Journal of Sports Economics, Vol. 6, No. 4, 2005, pp 347-358

Fort R. and Quirk J. Cross-subsidisation, Incentives and Outcomes in Professional Team Sports, Journal of Economic Literature, Vol. 33, No. 3, September, 1995, pp. 1265-1299

Fort R. and Quirk J. Owner Objectives and Competitive Balance, Journal of Sports Economics, Vol. 5, No. 1, February, 2004, pp 20-32

Humphreys B.R. Alternative Measures of Competitive Balance in Sports Leagues, Journal of Sports Economics, Vol. 3, No. 2, May, 2002, pp 133-148

Jennett N. Attendances, Uncertainty of Outcome and Policy in the Scottish Football League, Scottish Journal of Political Economy, Vol. 31, No. 2, 1984, pp 176-198

Jones J.C.H. The Economics of the National Hockey League, Canadian Journal of Economics, Vol. 2, No. 1, 1969, pp 1-20

Kendall T.D. Spillovers, Complementarities and Sorting in Labor Markets with an Application to Professional Sports, Southern Economic Journal. Vol. 70 (20), 2003, pp 389-402

Kesenne S. League Management in Professional Team Sports with Win Maximising Clubs, European Journal for Sports Management, Vol. 2, 1995, pp 14-22

Kesenne S. Player Market Legislation and Competitive Balance in a Win Maximising Scenario, in Jeanrenaud C. and Kesenne S., editors. Competition Policy in Professional Sports: Europe after the Bosman Case, Standard Editions, Antwerp, 1999

Kesenne S. Revenue Sharing and Competitive Balance in Professional Team Sports, Journal of Sports Economics, Vol. 1, No. 1, February, 2000, pp 56-65

Lipsey R.G. and Lancaster K. The General Theory of the Second Best, Review of Economic Studies, Vol. XXIV, October, 1956, pp 11-32

Marburger D.R. Gate Revenue Sharing and Luxury Taxes in Professional Sports, Contemporary Economic Policy, Vol. XV, April, 19197, pp 114-123

Moorhouse H.F. Football Post-Bosman: The Real Issues, in Jeanrenaud C. and Kesenne S., editors. Competition Policy in Professional Sports: Europe after the Bosman Case, Standard Editions, Antwerp, 1999

Neale W.C. The Peculiar Economics of Professional Sports, Quarterly Journal of Economics, Vol. 78, No. 1, 1964, pp 1-14 
Noll R.G. The Economics of Promotion and Relegation in Sports Leagues: The Case of English Football, Journal of Sports Economics, Vol. 3, No. 2, May, 2002, pp 169203

Rottenberg S. The Baseball Player's Labor Market, Journal of Political Economy, Vol. 64, No. 3, 1956, pp 242-258

Rottenberg S. Resource Allocation and Income Distribution in Professional Team Sports, Journal of Sports Economics, Vol. 1, No. 1, February, 2000, pp 11-20

Sloane P.J. The Labour Market in Professional Football, British Journal of Industrial Relations, Vol. 7, No. 2, 1969, pp 181-199

Sloane P.J. The Economics of Professional Football: The Football Club as a Utility Maximiser, Scottish Journal of Political Economy, Vol. 18, No. 2, June, 1971, pp 121-146

Szymanski S. and Kesenne S. Competitive Balance and Gate-Revenue Sharing in Team Sports, Journal of Industrial Economics, Vol. L11, No. 1, March 2004, pp 16177

Whitney J.D. The Peculiar Externalities of Professional Team Sports, Economic Inquiry, Vol. 43, No. 2, April, 2005, pp 330-343

Zimbalist A.S. Competitive Balance in Sports Leagues: An Introduction, Journal of Sports Economics, Vol. 3, No. 2, May 2002, pp 111-121 